REGARDS

SUR LEECONOMIE ALLEMAND

BULLETIN ECONOMIQUE DU CIRAC
Regards sur l'économie allemande

Bulletin économique du CIRAC

$66 \mid 2004$

Varia

\title{
Élargissement, mondialisation et innovation
}

René Lasserre

\section{OpenEdition}

Journals

Édition électronique

URL : http://journals.openedition.org/rea/3844

DOI : $10.4000 /$ rea. 3844

ISBN : 978-2-8218-0828-7

ISSN : 1965-0787

Éditeur

CIRAC

Édition imprimée

Date de publication : 1 mai 2004

Pagination : 1-2

ISSN : 1156-8992

Référence électronique

René Lasserre, «Élargissement, mondialisation et innovation », Regards sur l'économie allemande [En ligne], 66 | mai 2004, mis en ligne le 12 octobre 2009, consulté le 22 septembre 2020. URL : http:// journals.openedition.org/rea/3844 ; DOI : https://doi.org/10.4000/rea.3844 


\section{Élargissement, mondialisation et innovation}

Tirant parti d'une dynamique de croissance mondiale qui ne se dément pas, la situation économique allemande continue de se consolider et de s'embellir. Sous l'effet de la reprise des investissements, la machine industrielle allemande remonte progressivement en régime, confortant ainsi les perspectives d'une reprise durable d'activité et d'un recul progressif du chômage. Les perspectives d'une sortie de crise sont en effet meilleures que ne le laissent penser la nervosité des milieux économiques qui, redoublant d'impatience devant la lenteur des réformes, craignent de manquer le rendez-vous de la croissance.

Pourtant, certains signes ne trompent pas qui montrent que l'Allemagne est en train de réussir à rétablir ses "fondamentaux ", à commencer par la consolidation de ses finances publiques durement mises à mal par l'unification et la croissance ralentie des dernières années. Ce n'est pas un moindre satisfecit que vient de délivrer la Commission européenne en estimant que le déficit public allemand devrait repasser en dessous de la barre des $3 \%$ dès 2005. Autre signe encourageant d'une santé financière retrouvée : le rétablissement progressif du système bancaire qui, face à la plus grave crise qu'il ait connue depuis l'après-guerre, et au prix d'une cure sévère d'assainissement, s'est engagé dans une modernisation de ses structures et de ses règles de gestion des risques tout en préservant les principes d'organisation qui ont jusqu'à présent assuré la stabilité et la continuité du financement des entreprises.

Pour l'heure, l'une des principales préoccupations en Allemagne est celle de l'élargissement de l'Union européenne, considéré à la fois comme une chance et comme un risque. Avec l'entrée des nouveaux Etats membres de l'Europe centrale dans le grand marché, l'économie allemande bénéficiera d'un nouveau potentiel de croissance dont devraient profiter la plupart des grands secteurs de l'industrie qui y sont déjà fortement implantés. L'ouverture n'en comporte pas moins le risque d'une forte concurrence salariale dont pourraient souffrir les régions limitrophes, au premier rang les nouveaux Länder, ainsi que nombre de PME de sous-traitance. Mais au-delà des effets encore imprévisibles à court terme, l'impact économique de l'élargissement ne doit pas être surestimé : l'étude que nous présentons dans ce numéro sur l'enclavement de la Bohême, région industrielle située au carrefour de l'Europe élargie, montre que sans une politique européenne plus active de modernisation des infrastructures, l'ouverture des frontières ne suffira pas à elle seule à assurer un développement optimal des échanges.

La question de la localisation des activités dans une Europe élargie où la fluidité du marché et des échanges est encore loin d'être assurée n'en devient que plus aiguë et suscite de profondes inquiétudes. La relocalisation d'activités ne procède pas uniquement d'un effet d'aubaine. Elle s'inscrit également dans une logique économique d'investissement et de croissance, à la fois pour pouvoir répondre à la demande au sein d'un marché élargi et pour assurer le développement et le rattrapage industriels des nouveaux Etats membres, prélude au rééquilibrage économique et social de la nouvelle Europe. L'élargissement apparaît ainsi 
aux Européens les mieux nantis comme une contrainte supplémentaire de la mondialisation, car il implique un nouvel effort de compétitivité et d'adaptation des entreprises dans lequel l'innovation apparait comme le principal levier qui permet de compenser le différentiel de coûts de production au sein même du nouvel espace communautaire.

L'Europe ne peut décidément pas échapper au défi de l'économie du savoir. Et les Etats membres, France et Allemagne en tête, se trouvent désormais confrontées à l'enjeu crucial que constitue l'efficacité de leur système de formation initiale, d'enseignement supérieur et de recherche. Le dossier que nous présentons de la situation allemande montre, par-delà quelques spécificités et différences selon les secteurs, une singulière convergence de problèmes dans nos deux pays : recul des performances du système éducatif dans l'acquisition des compétences de base, sous-financement chronique et rigidités du système d'enseignement supérieur et de recherche. Autant de handicaps qui pénalisent la capacité de nos économies et de nos sociétés à se maintenir sur le marché mondial de l'innovation et du savoir et à tirer pleinement parti du nouvel espace européen de l'enseignement et de la recherche.

Notons toutefois que dans la comparaison France-Allemagne, notre voisin garde encore quelques longueurs d'avance dans les positions qu'il occupe au sein des réseaux de recherche européens. Et sans doute tout autant, sinon plus, dans sa capacité à assurer une interpénétration étroite et une coopération efficace entre formation, recherche et industrie dans le processus d'innovation. A la suite de nos études précédentes sur les biotechnologies et les nanotechnologies, l'état des lieux que nous dressons de la recherche allemande sur la pile à combustible en fournit une nouvelle illustration.

René Lasserre 26/04/2004 